\title{
Review
}

\section{Inflammatory Bowel Diseases and Parkinson's Disease}

\author{
Tomasz Brudek ${ }^{\mathrm{a}, \mathrm{b}, *}$ \\ ${ }^{a}$ Research Laboratory for Stereology and Neuroscience, Copenhagen University Hospital, \\ Bispebjerg-Frederiksberg Hospital, Copenhagen, Denmark \\ ${ }^{\mathrm{b}}$ Copenhagen Center for Translational Research, Copenhagen University Hospital, \\ Bispebjerg and Frederiksberg Hospital, Copenhagen, Denmark
}

Accepted 20 September 2019

\begin{abstract}
The etiology of Parkinson's disease (PD) is multifactorial, with genetics, aging, and environmental agents all a part of the PD pathogenesis. Widespread aggregation of the $\alpha$-synuclein protein in the form of Lewy bodies and Lewy neurites, and degeneration of substantia nigra dopamine neurons are the pathological hallmarks of PD. Inflammatory responses manifested by glial reactions, $\mathrm{T}$ cell infiltration, and increased expression of inflammatory cytokines, as well as other toxic mediators derived from activated glial cells, are currently recognized as prominent features of PD. Experimental, clinical and epidemiological data suggest that intestinal inflammation contributes to the pathogenesis of PD, and the increasing number of studies suggests that the condition may start in the gastrointestinal system years before any motor symptoms develop. Patients with inflammatory bowel disease (IBD) have a higher risk of developing PD compared with non-IBD individuals. Gene association study has found a genetic link between IBD and PD, and an evidence from animal studies suggests that gut inflammation, similar to that observed in IBD, may induce loss of dopaminergic neurons. Based on preclinical models of PD, it is suggested that the enteric microbiome changes early in PD, and gut infections trigger $\alpha$-synuclein release and aggregation. In this paper, the possible link between IBD and PD is reviewed based on the available literature. Given the potentially critical role of gastrointestinal pathology in PD pathogenesis, there is reason to suspect that IBD or its treatments may impact PD risk. Thus, clinicians should be aware of PD symptoms in IBD patients.
\end{abstract}

Keywords: Parkinson's disease, inflammatory bowel disease, Crohn's disease, ulcerative colitis, enteric nervous system, brain-gut axis, gastrointestinal track inflammation, inflammation

\section{INTRODUCTION}

The majority of Parkinson's disease (PD) patients experience non-motor-symptoms such as chronical constipation and/or impairment of gastrointestinal (GI) transit many years prior to disease onset [1-4]. The work by Braak and his colleagues suggested that the pathological process in PD originates in the

${ }^{*}$ Correspondence to: Tomasz Brudek, Research Laboratory for Stereology and Neuroscience, Copenhagen University Hospital, Bispebjerg-Frederiksberg Hospital, Nielsine Nielsens Vej 6B, building 11B, 2nd floor, DK-2400 Copenhagen NV, Denmark. Tel.: +45 38635600; E-mail: tomasz.brudek@ regionh.dk.
GI tract [5] and spreads from the enteric nervous system (ENS) via the vagus nerve to the central nervous system (CNS) in predictable stages [6], thereby affecting the brain and consequently resulting in neurodegeneration. Lewy pathology has been detected in the gut of PD patients and, thus, GI inclusions of $\alpha$-synuclein ( $\alpha$-syn) have been investigated as a potential biomarker for prodromal PD [7]. Accordingly, $\alpha$-syn immunostaining has been showed in distal colon tissue samples removed 2 to 5 years before the first reported symptom of PD in patients experiencing constipation prior to PD onset [8]. Subsequently, two multi-investigator blinded-panel 
evaluations of $\alpha$-syn pathology clearly established its selective, however inconsistent, presence in the PD colon and exclusion from controls $[9,10]$. However, no single staining method or staining pattern had a sensitivity and specificity of more than $80 \%$ [10].

This review will focus mainly on chronic inflammatory process in the GI tract, which makes up a connection between the surrounding environment and the CNS and thus function as an entry point for pathogens and other environmental factors that might predispose certain individuals to develop PD $[6,11]$. Recent studies have investigated the GI microbiome to elucidate whether the composition of the microbiome or eventually dysbiosis might play a role in intestinal inflammation and GI barrier-function in PD [12-15]. The inflammatory processes that have been found to occur in some patients with PD have naturally led to discussion of an association between inflammatory bowel disease (IBD) and PD since the two share some basic characteristics. IBD is characterized by chronic pro-inflammatory immune activity, a trait which is now suggested also to be a fundamental element of neurodegenerative disorders [16-18]. Therefore, intestinal inflammation may be of particular relevance in the pathogenesis of $\mathrm{PD}$.

\section{INFLAMMATORY BOWEL DISEASE}

In IBD, the tridirectional relationship between the commensal flora (microbiota), genetic susceptibility to disease development, and mucosal immune system is dysregulated, leading to chronic inflammation. Each of these three aspects is affected by genetic and environmental factors that determine the risk for the disease $[19,20]$. IBD is currently considered as an inappropriate immune response to the endogenous commensal microbiota within the intestines, with or without some components of autoimmunity [21, 22]. IBD includes Crohn's disease (CD) and ulcerative colitis (UC). CD can affect any part of the GI tract in a discontinuous transmural pattern. Active $\mathrm{CD}$ is characterized by focal inflammation and formation of fistula tracts, which resolve by fibrosis and structuring of the bowel. The bowel wall thickens, becomes narrowed and fibrotic, leading to chronic, recurrent bowel obstructions. UC typically involves the large intestine in an uninterrupted pattern with typical confinement to the mucosa leaving the deeper layers unaffected except in fulminant disease. The major symptoms of UC are diarrhea, rectal bleeding, tenes- mus, passage of mucus, and crampy abdominal pain [20].

In a PD rat model, bowel inflammation can exacerbate neuroinflammation and disrupt the blood-brain barrier (BBB), leading to dopaminergic neuronal loss in the substantia nigra [18]. Further, several studies have shown clinical evidence of bowel inflammation in PD patients [13, 16, 23]. However, the possible connection between inflammatory processes in the GI tract and PD questions whether IBD could constitute a risk factor for developing PD or eventually exacerbate disease progression.

\section{PD AND IBD: GENETIC BACKGROUND}

The association between $\mathrm{PD}$ and $\mathrm{CD}$ has been a focus point since it was discovered in genome-wide association studies (GWAS) that the leucine-rich repeat kinase 2 (LRRK2) gene is a common susceptibility-factor in both diseases [24-32]. LRRK2 mutations are now known to be the most common genetic cause of PD, accounting for $10 \%-40 \%$ of familial cases depending on the population studied [33]. Polymorphisms in the gene have also been linked to an increased risk of $\mathrm{CD}$ [32, 34, 35]. Unlike other PD-associated genes, LRRK2 associated parkinsonism manifests similar clinical phenotypes to idiopathic PD, displaying strong age-dependent development of PD symptoms [29]. LRRK2 is probably involved in the pathological interplay between peripheral and CNS innate immunity which contributes to the progression of PD. The expression of LRRK2 is tightly regulated in both systems [36]. Hui and colleagues identified recently a novel coding variant in the LRRK2 gene, N2081D, to be associated with increased risk for CD (OR, 1.73; $\mathrm{P}=2.56 \times 10-9$ ), after exome sequencing followed by array-based genotyping of 2066 cases and 3633 controls in the Ashkenazi Jewish population [32]. In addition, they identified a protective haplotype, which has previously also been shown to reduce risk in PD [37].

Despite these results, the following important question remains: how do these variants influence the disease mechanism? An obvious explanation could be that the gene-alterations predisposing to the two diseases are located at different positions on the gene or/and possibly also flanking regions that regulate gene expression (e.g. SNPs in promoter or non-coding regions) or in genes coregulated with LRRK2 [38]. The LRRK2 is a large protein with 
different domains providing several different cellular functions [39]. Since the alterations are located in different positions of the protein, they may affect different domains and thereby different pathways, different cellular processes and distinct pathological mechanisms. LRRK2-dysfunction in PD is associated with aberrant kinase or GTPase-activity which is not the case for IBD [40, 41]. The most prevalent LRRK2 mutations in PD have been shown to affect macroautophagy in various cellular models while a role in autophagy signaling has been recapitulated in vivo. Dysregulation of autophagy has been implicated in PD pathology, and this raises the possibility that differential autophagic activity is relevant to disease progression in PD patients carrying LRRK2 mutations. Indeed, recent data support a distinct molecular signature for LRRK2 PD compared to idiopathic PD, where dysregulation of vesicular trafficking and sequestration of lysosomal components underpins alterations in macroautophagy and protein clearance [42].

Another important factor is the cell type affected by $L R R K 2$ mutations. LRRK2 is expressed not only by the neurons and immune cells in human brain, but also peripheral myeloid cells express LRRK2 at high levels, and the expression of LRRK2 is upregulated by inflammatory signals [43-46]. It has been shown that a common risk variant at the $L R R K 2$ locus is associated with higher LRRK2 expression in microglia-like cells derived from human monocytes [47]. This suggests that the role of $L R R K 2$ risk variants may be more prominent under situations where microglia are stimulated. LRRK2 expression enhances transcriptional activation of inflammatory responses [44] and PD-linked mutations induce cytokine production in activated microglia [48]. Inhibition of $L R R K 2$, either by small-molecule kinase inhibitors or RNAi knockdown, attenuates microglial inflammatory responses [49] and LRRK2 deficiency impairs immune clearance in vivo [50].

In the gastrointestinal tract of $\mathrm{CD}$ patients, LRRK2 expression is restricted to lamina propria macrophages, dendritic cells and B-lymphocytes, and is induced by interferon- $\gamma$, which is consistent with its role in IBD [44]. A recent study has found high expression of LRRK2 in Paneth cells in the ileum, demonstrating that both NOD2 and LRRK2 are required for proper lysosomal sorting within Paneth cells [51]. Thus, in relation to genetic factors it is worth mentioning that polymorphisms in the CARD15/NOD2 gene is associated with CD $[28,52-54]$. This gene has been found to be overex- pressed in PD patients [55]. CARD15/NOD2 protein represents a pattern recognition receptor that plays a role in the initiation of inflammatory host immune responses [56] and CARD15/NOD2 mutations have been associated with the development of chronic IBD. Further, monocytes/macrophages derived from humans or mice with such mutations demonstrate altered NF-kB activity and inflammatory cytokine production [57, 58]. NOD2 receptors function as intracellular sensors to bacterial infections generating damaging CNS inflammation and they have been shown to be constitutively expressed in microglia and astrocytes [59].

Highlighting the relevance of the immune system, large GWAS and pathway analyses based on 138511 individuals of European ancestry identified 17 shared loci between PD and seven autoimmune diseases including celiac disease, rheumatoid arthritis, type 1 diabetes, multiple sclerosis, psoriasis, ulcerative colitis and Crohn's disease [38]. Among these autoimmune diseases, the strongest pleiotropic enrichment was observed between PD and Crohn's disease including both LRRK2 and MAPT genes. The findings further indicate that defects in cargo transport mechanism might underline the disease pathogenesis in both phenotypes. Another shared gene $H L A-D Q B 1$ involved in immune response and antigen presentation implicates overlapping factors related to the immune system. In agreement with the epidemiological findings (discussed in the next section), the GWAS found only moderate polygenic pleiotropic enrichment between PD and UC, whereas genetic enrichment with type 1 diabetes, celiac disease, psoriasis, and multiple sclerosis was very weak [38].

\section{EPIDEMIOLOGICAL EVIDENCE FOR A LINK BETWEEN IBD AND PD}

With consistent genetic and functional evidence established between PD and IBD, epidemiological studies have emerged investigating IBD as a risk factor for PD. In 2016, Lin et al. were first to investigate associations between PD and IBD in a Taiwanese nationwide retrospective cohort study. The study concluded that IBD was associated with a $35 \%$ increased risk of $\mathrm{PD}$ which was most pronounced in $\mathrm{CD}$ patients [60]. Another retrospective study by Fujioka et al. investigated the occurrence of CD with PD by searching the medical records of $876 \mathrm{PD}$ patients and subsequently looked for incidences of prior or cur- 
rent $\mathrm{CD}$. The study found that the co-occurrence of $\mathrm{CD}$ with PD was consistent with the number of cases expected in the general population [61]. However, limitations to this study was the relatively small number of subjects. Furthermore, the study was based on medical records and the research team did not perform any confirmatory tests to detect the presence of $\mathrm{CD}$ in the patients.

One year later, three large cohort studies from Denmark, Sweden and USA were published [62-65]. In the Danish study, we have shown that IBD patients have a $22 \%$ increased risk of $\mathrm{PD}$ as compared with non-IBD individuals ( $\mathrm{HR}=1.22 ; 95 \%$ CI 1.09 to 1.35). When stratifying, the increased risk of parkinsonism was significantly higher among patients with UC but not with CD [62]. In the Swedish and American studies, the increased PD hazard ratio was observed for both UC and CD [64, 65]. In a recent, Korean nationwide population-based study of approximately 160,000 individuals, including 39,000 IBD patients and a mean follow-up of 5 years, CD and UC patients were at 2.2- and 1.9-times higher risk for PD than controls, respectively [66]. Furthermore, American patients with IBD who were prescribed anti-TNF therapy had a lower risk of developing PD than those patients with IBD who were not treated with anti-TNF [65]. In the Korean study none of the IBD patients receiving TNF anti-TNF agents developed PD and steroid therapy reduced the risk of developing PD by $92 \%$ among CD patients [66]. This further supports a causal role of inflammation in PD and a potential benefit of targeting peripheral TNF. Interestingly, a lower risk of PD was observed in individuals with IBD aged $\leq 65$ years and treated with mesalazine (5-aminosalicylic acid (5-ASA)) or its derivative sulfasalazine, the first-line anti-inflammatory treatment in UC [67, 68].

It is important to underline at this point that only a very small fraction of IBD patients develops PD. In yet another case-control study enrolling patients aged 65 years or older with newly diagnosed PD $(n=89,790)$ and controls $(n=118,095)$, an inverse correlation between PD and IBD has been shown, suggesting that patients with IBD are less likely to develop PD [69]. All population studies were summarized in an elegant meta-analysis by Zhu et al., demonstrating $46 \%$ increased risk of PD in IBD patients compared to controls. The increased risk remained significant when separately analyzing $C D$ and UC groups [70].

Cigarette smoking habit is yet another epidemiological evidence for a connection between PD and
IBD, which, however, should be taken with a grain of salt. A meta-analysis from 1989 has shown that tobacco smoking is associated with a reduced risk of developing UC (in contrast to CD) [71]. UC appears to be predominantly a disease of ex-smokers and nonsmokers as reviewed by [72]. Similar to UC, long-term smoking also reduces the risk of PD [73]. Compared with never-smokers, the risk of PD was shown to be $58 \%$ lower in current smokers and $41 \%$ lower in ever-smokers. The biological mechanism behind the protective effects of smoking in UC and $\mathrm{PD}$ remains to be clarified, but it is known that both smoking and nicotine affect the composition of the microbiota and reduce the production of proinflammatory cytokines [74]. Nicotine also stimulates dopaminergic neurons, relieves PD symptoms, and possesses a neuroprotective effect [75]. Interestingly, a cohort study by Ritz et al. based on Danish registries showed that PD patients quit smoking more easily than unaffected controls [76]. This may suggest a decreased responsiveness to nicotine as an event prodromal to PD. Further, this may indicate a reverse causation as the primary explanation for this apparent association between PD risk and tobacco use [76].

\section{EVIDENCE FROM ANIMAL MODELS OF GI INFLAMMATION}

Prior to the onset of motor features, many PD patients exhibit a variety of non-motor symptoms including constipation, sleep disorder, depression, and hyposmia [77-79]. Most of the GI dysfunctions are accompanied by inflammatory processes which play a critical role in the pathology of PD. Already in 1965, it was described that the increased prevalence of peptic ulcer is prodromal to idiopathic parkinsonism [80]. In a well-characterized model of experimental colitis peripheral inflammation is usually induced by oral dextran sulfate sodium (DSS) administration [81]. The mice quickly develop symptoms similar to those observed in UC patients including hematochezia diarrhea and loss of body weight. Villarán et al. used the experimental colitis model to show that inflammatory responses in the gut lead to an increase in the levels of inflammatory markers in the substantia nigra $(\mathrm{SN})$ including TNF- $\alpha$, GFAP and IL-6 [18]. In the study, the rats were injected with lipopolysaccharide (LPS) in the $\mathrm{SN}$ and the study concluded that experimental colitis reinforced the inflammatory and deleterious effects of LPS and loss of dopaminergic neurons [18]. Also, 
chronic mild gut inflammation induced by a low concentration of DSS in the drinking water $(0.5 \%)$ is sufficient to accelerate the onset of motor dysfunction in an animal model of PD, a mouse overexpressing human mutant (A53T) $\alpha$-syn [82]. The authors observed that the age of onset of motor dysfunction was significantly earlier, and $\alpha$-syn pathology and dopamine neuron degeneration were exacerbated in DSS-treated PD mice [82].

The question remains whether the peripheral inflammation must be of gut origin or whether peripheral inflammation, as such, is a risk factor by itself, and not only as a factor contributing to neurodegeneration. Carrageenan, an extract of Irish moss (Chondrus crispus), is commonly used to produce short-lasting acute inflammation and hyperalgesia in animal models [83]. In 2012, a Spanish group tested the influence of a mild to moderate peripheral inflammation (injection of carrageenan into the paws of rats) on the degeneration of dopaminergic neurons in an animal model based on the intranigral LPS injection [84]. Here as well, the challenge with carrageenan increased the detrimental effects of the intranigral injection of LPS on dopaminergic neuron survival and was accompanied by increased serum levels of TNF$\alpha$, IL-1 $\beta$, IL-6 and C-reactive protein; activation of microglia, loss of astrocytes and damages to the BBB. Recently, this has been supported by a report showing that DSS-induced experimental colitis increases systemic inflammation which then results in cortical inflammation via up-regulation of serum cytokines [85]. Mice with acute or subchronic gut inflammation manifest early changes in the nigrostriatal dopaminergic homeostasis, dopaminergic neuron death, and increased levels of nigral pro-inflammatory markers and renin-angiotensin system (RAS) proinflammatory activity [86]. Interestingly, there was no significant increase in colonic $\alpha$-syn and phosphorylated (p)- $\alpha$-syn expression during the relatively short survival period. Moreover, in the same study a decrease in dopaminergic function (i.e., central dopaminergic degeneration) led to GI disturbances and an increase in GI inflammatory responses [86]. This neural bidirectional gut-brain interaction may explain the early gut disturbances observed in parkinsonian patients, and the increased vulnerability of nigral dopaminergic neurons following gut inflammation [87].

The above-mentioned animal studies link inflammatory processes in the GI tract to loss of dopaminergic neurons and by that suggest a mechanism of how GI inflammation may contribute to the development or progression of parkinsonian symptoms.

A very recent, elegant animal study has presented another evidence for a critical role of intestinal inflammation and $\alpha$-syn accumulation in the initiation and progression of PD. Grathwohl et al. have recapitulated human PD pathology in an animal model showing that $\alpha$-syn accumulates in the large intestine of $\alpha$-syn transgenic as well as wildtype mice subjected to experimental colitis and that this process seemed to be modulated by monocyte/macrophagerelated signaling [88]. Interestingly, experimental colitis in transgenic mice at a young age led to an exacerbation of $\alpha$-syn pathology in the brain later in life resulting in severe neurodegeneration. Unfortunately, the authors did not perform vagotomy which could be a convincing evidence for the involvement of vagal nerve in transfer of $\alpha$-syn pathology. In another 2019 study, Resnikoff et al. utilized nonhuman primates, common marmosets, with colitis to show that inflammation may trigger $\alpha$-syn pathology in the ENS of the gut. Marmosets with colitis had significantly increased expression of inflammatory markers and $\mathrm{p}-\alpha$-syn, and decreased expression of $\alpha$-syn in the colonic myenteric ganglia [89].

\section{GASTROINTESTINAL TRACT INFLAMMATION OF PATIENTS WITH PD}

GI symptoms are among the most bothersome of PD symptoms. In a cohort study from the early $90 \mathrm{~s}$ it has been shown that those symptoms occurred more frequently in PD patients than in controls including abnormal salivation, dysphagia, nausea, constipation, and defecatory dysfunction. Except for defecatory dysfunction, symptoms did not correlate with treatment but instead correlated with disease severity $[90$, 91].

Lewy pathology affects the GI tract in PD [92-94]. PD mice show a strong immune response in the gut [95], and colonic biopsies of PD patients show evidence of a structural dysfunction of the intestinal barrier, reinforcing the idea of a role of the GI tract in the initiation and/or the progression of the disease $[96,97]$. Enteric inflammation occurs in PD which further strengthen the role of peripheral inflammation in the pathophysiology of PD [16]. Further, in non-human primates, colitis-associated inflammation is concomitant to alterations in $\alpha$-syn and $\mathrm{p}-\alpha$-syn expression in colonic myenteric ganglia [89]. Autopsy studies performed on human subjects with 
Lewy Body disorders have consistently shown that $\alpha$ syn aggregates are found in the ENS in nearly every case examined $[92,93,98]$. Still there is a lack of evidence from prodromal PD GI samples which could help to establish a better link between PD initiation and GI inflammation.

CNS glial activation, characterized by micro- and astrogliosis, is a well-defined feature of an activated neuroinflammatory response. The ENS likewise contains a prominent component of glial cells, the so-called enteric glial cells, which, like astrocytes of the CNS, contribute to support, protect, and maintain the neural network [99]. Enteric glial cells have different physiological roles depending on their location within the GI wall [100]. They are located in the GI mucosa beneath the epithelial cells and have an influence on the epithelial barrier function. Both IBD and PD have been associated with GI barrier dysfunction and furthermore, the GI symptoms that occur in PD might in part be caused by enteric glial dysfunction [96, 101]. Enteric glial cells are in a close proximity of gut epithelial cells, and similarly to their counterparts in the CNS they may affect intestinal permeability through the release of several mediators, directly controlling epithelial barrier functions [102]. Abnormalities in the form of morphological changes have also been found in patients with IBD [103]. Enteric inflammation in PD is closely associated with glial dysregulation and evidence suggests that enteric glial cells are key players in regulating gastrointestinal inflammation [16]. Intestinal permeability in PD correlates with levels of $\alpha$-syn as well as indicators of oxidative stress [104].

Devos et al. performed a study where a putative co-occurrence of gut inflammation in PD patients was investigated. It was concluded that the mRNA-expression levels of pro-inflammatory cytokines were significantly elevated in the ascending colon of PD patients [16]. Levels of the commonly used enteric glial markers GFAP and Sox-10 were strongly correlated with the amount of several proinflammatory cytokines, including IL-6, which is released after enteric glial cell activation [105]. The pro-inflammatory profile of cytokines seen in patients with PD was very similar to the cytokine profile seen in patients with IBD. For example, an increase in the expression of IL- $1 \beta$ and TNF- $\alpha$ have been associated with both PD and IBD [106, 107]. It is important to emphasize that not all PD patients show identical pro-inflammatory profiles.

Recently, calprotectin, a fecal marker of intestinal inflammation, as well as alpha-1-antitrypsin and zonulin (both fecal markers of intestinal permeability) have shown to be significantly elevated in PD patients when compared to controls [23]. Interestingly, the inflammatory marker profile in PD patients shared some similarities to what has been reported in IBD [108]. Another study from the same year analyzed immune and angiogenesis factors in stool to assess the GI inflammatory state in PD patients, their healthy spouses, and unrelated healthy control subjects [13]. In this study, they found elevated levels of proinflammatory factors such as IL- $1 \alpha$, IL$1 \beta$, chemokine ligand 8 (CXCL8) and C-reactive protein (CRP). Additionally, the authors showed that disease-associated patterns in levels of immune factors did not change with PD duration which suggests that intestinal inflammation is not exclusively present in advanced disease state. Based on that they hypothesize that intestinal inflammation is an early manifestation of PD that could contribute to the development of neuropathology rather than an effect arising in response to extensive GI neurodegeneration.

\section{ALPHA-SYNUCLEIN AND IBD}

As mentioned earlier, in PD, the presynaptic protein $\alpha$-syn undergoes pathological changes, including phosphorylation and aggregation leading to the formation of Lewy bodies, which can be also found in neurons of the ENS. Therefore, yet another natural evidence suggesting a relationship between colonic inflammation and PD would be the search for $\alpha$-syn aggregates in ENS of GI patients. CD patients show a significant 2-3-fold increase in the levels of $\alpha$-syn protein in the non-inflamed and inflamed area of GI tract when compared to controls. Interestingly, these differences were not observed in UC patients, and there were no differences in the immunoreactivity for $\alpha$-syn or $p-\alpha$-syn between large intestine samples from CD, UC and controls [109]. The authors suggested that some of the pro-inflammatory cytokines and/or para-inflammatory responses that are activated in $\mathrm{CD}$, but not in $\mathrm{UC}$, are involved in the regulation of $\alpha$-syn expression. Soon after, a new study showed substantial intracellular $\alpha$-syn staining in infiltrating monocytic cells from colonic biopsies in 8/11 UC cases, and 4/11 patients with CD and almost none in healthy individuals [88].

Accumulation of $\alpha$-syn is not necessarily specific to IBD but it is also related to GI inflammation and $\alpha$-syn is a regulator of the immune system including 
certain innate immune cells $[110,111]$. A study from 2017 on pediatric patients, reported a positive correlation between the expression of $\alpha$-syn in the enteric neurites of the upper GI tract and the degree of acute and chronic inflammation in the intestinal wall [112]. This study also reported an intra-patient increase in expression of $\alpha$-syn before and after norovirus infection.

Extracellular $\alpha$-syn may accumulate due to impairment of the microglial phagocytic molecular machinery. It has been shown that excess $\alpha$-syn compromises phagocytosis as demonstrated by measuring fibrillar $\alpha$-syn uptake in iPSC-derived macrophages from PD patients with $\alpha$-syn (SNCA) A53T and SNCA triplication [113].

It is worthy of note that $\alpha$-syn aggregates are also seen in the ENS of normally aging subjects [114], especially in the appendix [115]. A recent comprehensive epidemiological study describing decreased incidence of PD in patients that had appendectomies illustrate a relationship between PD and GI tract health and function [116]. This suggests that the normal human appendix contains pathogenic forms of $\alpha$-syn that affect the risk of developing PD.

Overall, these reports provide some evidence for the hypothesis that colonic inflammation is capable of altering $\alpha$-syn in the ENS, however, induction of this protein within the ENS may be a part of the normal immune defense mechanism [112, 117, 118].

\section{GUT-BRAIN AXIS THEORY}

Based on increasing experimental evidence as to the connection between the intestinal environment and the CNS, the so-called 'gut-brain axis theory' has been proposed which consists of bidirectional communication between the CNS and the ENS, linking emotional and cognitive centers of the brain with peripheral intestinal functions [119].

According to this hypothesis, PD can be a consequence of intestinal dysbiosis and/or intestinal barrier dysfunction caused by an unknown pathogen within the GI. Such dysbiosis may be a reason for $\alpha$-syn aggregation in submucosal neurons and/or impact immune and inflammatory pathways leading to the peripheral and central immune activation and inflammation.

IBD is clearly associated with intestinal dysbiosis, however, no single microbe or microbial milieu has been proven causal. Recent advances in nextgeneration sequencing technologies have identified alterations in the composition and function of the gut microbiota. The decrease of bacteria with antiinflammatory capacities and the increase of bacteria with inflammatory capacities are observed in patients with IBD when compared to healthy individuals [120, 121]. Similar to IBD, PD patients exhibit a proinflammatory microbiota profile with a reduction in beneficial products such as short chain fatty acids [12, 122-125]. Colonization of $\alpha$-syn-overexpressing mice with microbiota from PD-affected patients enhances physical impairments compared to microbiota transplants from healthy human donors. Further, short chain fatty acids (SCFA), produced by the intestinal microbiome, increased the presence of $\alpha$ syn aggregates in the basal ganglia and SN [126]. Certain microbiome derived SCFA have also been implicated as modulators of microglia cell development and activation [127].

The gut microbiome and its effect on PD is not within the scope of the present review as it is covered by others in this special issue of the Journal of Parkinson's disease. However, evidence indicates that communication between the microbiota and the brain involves the vagus nerve, which transmits information from the luminal environment to the CNS. In fact, neurochemical and behavioral effects were not present in vagotomized mice, identifying the vagus as the major modulatory constitutive communication pathway between microbiota and the brain [128]. $\alpha$-syn from PD patient brain lysate injected into the gastric wall of rodents is taken up and transported retrogradely over a long distance via the vagal nerves from the gut to the dorsal motor nucleus of the brainstem in a time-dependent manner [129]. A very recent study provides an immunohistochemical evidence for propagation of initially localized enteric $\alpha$-syn pathology through the autonomic nervous system to the brain in a transgenic rodent model [130]. This is yet another indication suggesting the exclusive link between the brain and the gut, and a pathway to spread the pathological protein to the brain according to the Braak's theory [5, 131]. Further, their model also shows secondary anterograde (vagus-to-stomach) spreading of $\alpha$-syn which is the first indication of bidirectional $\alpha$-syn propagation via the vagus nerve [130]. In yet another animal study pathological $\alpha$-syn preformed fibrils were injected into the duodenal and pyloric muscularis layer causing retrograde, polysynaptic spreading of pathology into the brain which was further hampered by truncal vagotomy [132]. This supported an earlier evidence based on the rotenone gavage animal model showing 
that PD-like pathology progression occurs through sympathetic and parasympathetic nerves and that the scission of these nerves is sufficient to stop the progression of the pathology into the CNS [133].

Pathological forms of $\alpha$-syn delivered directly to the ENS are able to cause a GI phenotype in the form of reduced colonic motility in an animal model [134]. Interestingly, the data from this study suggest that $\alpha$-syn can be transported from ENS to the CNS brainstem in both rodents and non-human primates, however, the pathology was neither sustained, nor did it spread. The different outcomes of animal studies can be due to different methodologies and models, including lower amounts and different forms of delivered pathological $\alpha$-syn, time after injection and site of injection. Thus, the hypothesis of gut to brain propagation is still highly debated in the field and evidence in humans is still controversial [135].

In cohort studies with follow-up from northern Europe, individuals who underwent truncal vagotomy had a lower risk of developing PD than age- and sex-matched control individuals [136-138]. A larger population-based study is still needed as the evidence is inconsistent and the existing attempts had limited statistical power to examine the potential long-term effect of truncal vagotomy on PD.

\section{CONCLUSIONS}

The relatively new idea that the earliest stages of PD may occur in the GI tracts has been gaining attraction in recent years. Increasing evidence supports the hypothesis of pathological interplay between peripheral and CNS innate immunity probably contributes to initiation and progression of PD. The chronic activation of pro-inflammatory mechanisms, which occurs in autoimmune conditions, has been increasingly recognized as a critical contributor of neurodegenerative disorders. Given the potentially critical role of GI pathology in PD pathogenesis, there is reason to suspect that IBD or its treatments may impact PD risk, thus, clinicians should be aware of PD symptoms in IBD patients. More biomarker and observational studies are needed to identify IBD patients at risk to develop PD in order to start potential new therapies for PD. It is, however, important to state at this point that IBD only increases the risk of developing PD, and only a small fraction of IBD patients develops PD [65]. For a given IBD patient the risk of getting PD is still very small and the probability of not getting the diagnosis is $>95-97 \%$. Inflammation of the GI is only one of many symptoms on the list of changes in the gut and its associated neural structures in PD patients thus IBD might be just one of many sources of intestinal inflammation. The Braak's theory of pathological changes typically developing in predictable stages was strengthened by the observation that in post-mortem samples of PD patients, Lewy bodies are seen in both the brain and the GI nervous system that controls the function of the gut. The vagus nerve may be the relevant route through which PD pathological factors travel from the GI tract to the brain, but the convincing evidence still needs to be provided.

The obvious question is the mechanism by which the inflammation state in the GI tract can contribute to the dopaminergic degeneration in different circumstances and different PD patients. Those mechanisms may involve:

1) GI accumulation of $\alpha$-syn that retrogradely and slowly is being transported to the CNS,

Parallel, but similar processes that simultaneously affect central and peripheral dopaminergic neurons,

2) Peripheral inflammation, due to chronically inflamed gut, may trigger $\alpha$-syn deposition, increase the permeability of the gut and the BBB leading to neuroinflammation,

3) Inadequate signaling and metabolites from the gut microbiome may occur in addition to the dysregulation of the gut-brain dopaminergic crosstalk.

It is still possible that PD begins in a different region of the body or is a systemic disease in which the final stage manifests as a neurodegenerative disorder. Non-motor symptoms often precede the onset of motor dysfunction. PD patients have been observed to have more psychological, musculoskeletal, and cardiovascular symptoms and hence visit their general practitioners more often than control subjects during the prodromal phase [139].

A new conceptual model for PD pathogenesis proposed by Johnson et al., in which disease-associated factors are divided into three categories: triggers, facilitators, and aggravators, describes in an elegant manner a multifactorial etiology of PD [140]. Based on this model, pharmacological therapies aiming at slowing or arresting PD progression should not only be given to patients enriched for the appropriate target, but also be administered in the relevant phases of the disease [140]. 
Therefore, a clear knowledge of the mechanisms implicated in gut/immune/nervous communication could help improve the prognostic and therapeutic tools leading to better quality of life of the patients, reducing the exacerbation of $\mathrm{PD}$ symptoms, and delaying the progression of the disease.

\section{CONFLICT OF INTEREST}

The author has no conflict of interest to report.

\section{REFERENCES}

[1] Siddiqui M, Rast S, Lynn M, Auchus A, Pfeiffer R (2002) Autonomic dysfunction in Parkinson's disease: A comprehensive symptom survey. Parkinsonism Relat Disord 8, 277-284.

[2] Cheon S-M, Ha M-S, Park M, Kim J (2008) Nonmotor symptoms of Parkinson's disease: Prevalence and awareness of patients and families. Parkinsonism Relat Disord 14, 286-290.

[3] Martinez-Martin P, Schapira A, Stocchi F, Sethi K, Odin P, MacPhee G, Brown RG, Naidu Y, Clayton L, Abe K, Tsuboi Y, MacMahon D, Barone P, Rabey M, Bonuccelli U, Forbes A, Breen K, Tluk S, Olanow WC, Thomas S, Rye D, Hand A, Williams AJ, Ondo W, Chaudhuri RK (2007) Prevalence of nonmotor symptoms in Parkinson's disease in an international setting; Study using nonmotor symptoms questionnaire in 545 patients. Mov Disord 22, 1623-1629.

[4] Saleem TZ, Higginson IJ, Chaudhuri RK, Martin A, Burman R, Leigh NP (2013) Symptom prevalence, severity and palliative care needs assessment using the Palliative Outcome Scale: A cross-sectional study of patients with Parkinson's disease and related neurological conditions. Palliative Med 27, 722-731.

[5] Braak H, de Vos R, Bohl J, Tredici K (2006) Gastric $\alpha$-synuclein immunoreactive inclusions in Meissner's and Auerbach's plexuses in cases staged for Parkinson's disease-related brain pathology. Neurosci Lett 396, 67-72.

[6] Klingelhoefer L, Reichmann H (2015) Pathogenesis of Parkinson disease - the gut-brain axis and environmental factors. Nat Rev Neurol 11, 625-636.

[7] Ruffmann C, Parkkinen L (2016) Gut feelings about alphasynuclein in gastrointestinal biopsies: Biomarker in the making? Mov Disord 31, 193-202.

[8] Shannon KM, Keshavarzian A, Dodiya HB, Jakate S, Kordower JH (2012) Is alpha-synuclein in the colon a biomarker for premotor Parkinson's disease? Evidence from 3 cases. Mov Disord 27, 716-719.

[9] Beach TG, Corbillé A-G, Letournel F, Kordower JH, Kremer T, Munoz DG, Intorcia A, Hentz J, Adler CH, Sue LI, Walker J, Serrano G, Derkinderen P (2016) Multicenter assessment of immunohistochemical methods for pathological alpha-synuclein in sigmoid colon of autopsied Parkinson's disease and control subjects. J Parkinsons Dis 6, 761-770.

[10] Corbillé A-G, Letournel F, Kordower JH, Lee J, Shanes E, Neunlist M, Munoz DG, Derkinderen P, Beach TG (2016) Evaluation of alpha-synuclein immunohistochemical methods for the detection of Lewy-type synucleinopathy in gastrointestinal biopsies. Acta Neuropathol Commun $\mathbf{4}, 35$.

[11] Abbott RD, Ross WG, Petrovitch H, Tanner CM, Davis DG, Masaki KH, Launer LJ, Curb DJ, White LR (2007) Bowel movement frequency in late-life and incidental Lewy bodies. Mov Disord 22, 1581-1586.

[12] Keshavarzian A, Green SJ, Engen PA, Voigt RM, Naqib A, Forsyth CB, Mutlu E, Shannon K (2015) Colonic bacterial composition in Parkinson's disease. Mov Disord 30, 13511360.

[13] Houser MC, Chang J, Factor SA, Molho ES, Zabetian CP, Hill-Burns EM, Payami H, Hertzberg VS, Tansey MG (2018) Stool immune profiles evince gastrointestinal inflammation in Parkinson's disease. Mov Disord 33, 793-804.

[14] Gerhardt S, Mohajeri HM (2018) Changes of colonic bacterial composition in Parkinson's disease and other neurodegenerative diseases. Nutrients 10, 708.

[15] Hill-Burns EM, Debelius JW, Morton JT, Wissemann WT, Lewis MR, Wallen ZD, Peddada SD, Factor SA, Molho E, Zabetian CP, Knight R, Payami H (2017) Parkinson's disease and Parkinson's disease medications have distinct signatures of the gut microbiome. Mov Disord 32, 739749.

[16] Devos D, Lebouvier T, Lardeux B, Biraud M, Rouaud T, Pouclet H, Coron E, des Varannes S, Naveilhan P, Nguyen J-M, Neunlist M, Derkinderen P (2013) Colonic inflammation in Parkinson's disease. Neurobiol Dis 50, 42-48.

[17] Machado A, Herrera A, Venero J, Santiago M, Pablos DR, Villarán R, Espinosa-Oliva A, Argüelles S, Sarmiento M, Delgado-Cortés M, Mauriño R, Cano J (2011) Peripheral inflammation increases the damage in animal models of nigrostriatal dopaminergic neurodegeneration: Possible implication in Parkinson's disease incidence. Adv Neurol 2011, 393769.

[18] Villarán RF, Espinosa-Oliva AM, Sarmiento M, Pablos RM, Argüelles S, Delgado-Cortés MJ, Sobrino V, Rooijen N, Venero JL, Herrera AJ, Cano J, Machado A (2010) Ulcerative colitis exacerbates lipopolysaccharide-induced damage to the nigral dopaminergic system: Potential risk factor in Parkinson's disease. J Neurochem 114, 1687 1700 .

[19] Zhao M, Burisch J (2019) Impact of genes and the environment on the pathogenesis and disease course of inflammatory bowel disease. Digest Dis Sci 64, 17591769.

[20] Abraham C, Cho JH (2009) Inflammatory bowel disease. N Engl J Med 361, 2066-2078.

[21] Zhang YZ, Li YY (2014) Inflammatory bowel disease: Pathogenesis. World J Gastroenterol 20, 91-99.

[22] Wen Z, Fiocchi C (2004) Inflammatory bowel disease: Autoimmune or immune-mediated pathogenesis? Clin Dev Immunol 11, 195-204.

[23] Schwiertz A, Spiegel J, Dillmann U, Grundmann D, Bürmann J, Faßbender K, Schäfer K-H, Unger MM (2018) Fecal markers of intestinal inflammation and intestinal permeability are elevated in Parkinson's disease. Parkinsonism Relat Disord 50, 104-107.

[24] Franke A, McGovern DP, Barrett JC, Wang K, RadfordSmith GL, Ahmad T, Lees CW, Balschun T, Lee J, Roberts $\mathrm{R}$, Anderson CA, Bis JC, Bumpstead S, Ellinghaus D, Festen EM, Georges M, Green T, Haritunians T, Jostins L, Latiano A, Mathew CG, Montgomery GW, Prescott NJ, Raychaudhuri S, Rotter JI, Schumm P, Sharma Y, Simms LA, Taylor KD, Whiteman D, Wijmenga C, 
Baldassano RN, Barclay M, Bayless TM, Brand S, Büning C, Cohen A, Colombel J-F, Cottone M, Stronati L, Denson T, Vos M, D'Inca R, Dubinsky M, Edwards C, Florin T, Franchimont D, Gearry R, Glas J, Gossum A, Guthery SL, Halfvarson J, Verspaget HW, Hugot J-P, Karban A, Laukens D, Lawrance I, Lemann M, Levine A, Libioulle C, Louis E, Mowat C, Newman W, Panés J, Phillips A, Proctor DD, Regueiro M, Russell R, Rutgeerts P, Sanderson J, Sans M, Seibold F, Steinhart HA, Stokkers PC, Torkvist L, Kullak-Ublick G, Wilson D, Walters T, Targan SR, Brant SR, Rioux JD, D’ Amato M, Weersma RK, Kugathasan S, Griffiths AM, Mansfield JC, Vermeire S, Duerr RH, Silverberg MS, Satsangi J, Schreiber S, Cho JH, Annese V, Hakonarson H, Daly MJ, Parkes M (2010) Genome-wide meta-analysis increases to 71 the number of confirmed Crohn's disease susceptibility loci. Nat Genet 42, 1118-1125.

[25] Cookson MR (2010) The role of leucine-rich repeat kinase 2 (LRRK2) in Parkinson's disease. Nat Rev Neurosci 11, 791-797.

[26] Kumari U, Tan E (2009) LRRK2 in Parkinson's disease: Genetic and clinical studies from patients. FEBS $J \mathbf{2 7 6}$, 6455-6463.

[27] Barrett JC, Hansoul S, Nicolae DL, Cho JH, Duerr RH, Rioux JD, Brant SR, Silverberg MS, Taylor KD, Barmada MM, Bitton A, Dassopoulos T, Datta LW, Green T, Griffiths AM, Kistner EO, Murtha MT, Regueiro MD, Rotter JI, Schumm LP, Steinhart AH, Targan SR, Xavier RJ; NIDDK IBD Genetics Consortium, Libioulle C, Sandor C, Lathrop M, Belaiche J, Dewit O, Gut I, Heath S, Laukens D, Mni M, Rutgeerts P, Van Gossum A, Zelenika D, Franchimont D, Hugot JP, de Vos M, Vermeire S, Louis E; Belgian-French IBD Consortium; Wellcome Trust Case Control Consortium, Cardon LR, Anderson CA, Drummond H, Nimmo E, Ahmad T, Prescott NJ, Onnie CM, Fisher SA, Marchini J, Ghori J, Bumpstead S, Gwilliam R, Tremelling M, Deloukas P, Mansfield J, Jewell D, Satsangi J, Mathew CG, Parkes M, Georges M, Daly MJ (2008) Genome-wide association defines more than 30 distinct susceptibility loci for Crohn's disease. Nat Genet $\mathbf{4 0 ,}$ 955-962.

[28] Hugot J-P, Chamaillard M, Zouali H, Lesage S, Cézard J-P, Belaiche J, Almer S, Tysk C, O'Morain CA, Gassull M, Binder V, Finkel Y, Cortot A, Modigliani R, Laurent-Puig P, Gower-Rousseau C, Macry J, Colombel J-F, Sahbatou M, Thomas G (2001) Association of NOD2 leucine-rich repeat variants with susceptibility to Crohn's disease. Nature 411, 599.

[29] Healy DG, Falchi M, O'Sullivan SS, Bonifati V, Durr A, Bressman S, Brice A, Aasly J, Zabetian CP, Goldwurm S, Ferreira JJ, Tolosa E, Kay DM, Klein C, Williams DR, Marras C, Lang AE, Wszolek ZK, Berciano J, Schapira AH, Lynch T, Bhatia KP, Gasser T, Lees AJ, Wood NW, International LRRK2 Consortium (2008) Phenotype, genotype, and worldwide genetic penetrance of LRRK2-associated Parkinson's disease: A case-control study. Lancet Neurol 7, 583-590.

[30] Monfrini E, Fonzo A (2017) Leucine-rich repeat kinase 2 (LRRK2). Adv Neurobiol 14, 3-30.

[31] Bardien S, Lesage S, Brice A, Carr J (2011) Genetic characteristics of leucine-rich repeat kinase 2 (LRRK2) associated Parkinson's disease. Parkinsonism Relat Disord 17, 501-508.

[32] Hui KY, Fernandez-Hernandez H, Hu J, Schaffner A, Pankratz N, Hsu N-Y, Chuang L-S, Carmi S, Villaverde
N, Li X, Rivas M, Levine AP, Bao X, Labrias PR, Haritunians T, Ruane D, Gettler K, Chen E, Li D, Schiff ER, Pontikos N, Barzilai N, Brant SR, Bressman S, Cheifetz AS, Clark LN, Daly MJ, Desnick RJ, Duerr RH, Katz S, Lencz T, Myers RH, Ostrer H, Ozelius L, Payami H, Peter Y, Rioux JD, Segal AW, Scott WK, Silverberg MS, Vance JM, Ubarretxena-Belandia I, Foroud T, Atzmon G, Pe'er I, Ioannou Y, McGovern DP, Yue Z, Schadt EE, Cho JH, Peter I (2018) Functional variants in the LRRK2 gene confer shared effects on risk for Crohn's disease and Parkinson's disease. Sci Transl Med 10, eaai7795.

[33] Hardy J (2010) Genetic analysis of pathways to Parkinson disease. Neuron 68, 201-206.

[34] Umeno J, Asano K, Matsushita T, Matsumoto T, Kiyohara Y, Iida M, Nakamura Y, Kamatani N, Kubo M (2011) Meta-analysis of published studies identified eight additional common susceptibility loci for Crohn's disease and ulcerative colitis. Inflamm Bowel Dis 17, 2407-2415.

[35] Michail S, Bultron G, Depaolo RW (2013) Genetic variants associated with Crohn's disease. Appl Clin Genet 6, 25-32.

[36] Lee H, James WS, Cowley SA (2017) LRRK2 in peripheral and central nervous system innate immunity: Its link to Parkinson's disease. Biochem Soc Trans 45, 131-139.

[37] Ross OA, Soto-Ortolaza AI, Heckman MG, Aasly JO, Abahuni N, Annesi G, Bacon JA, Bardien S, Bozi M, Brice A, Brighina L, Broeckhoven C, Carr J, Chartier-Harlin MC, Dardiotis E, Dickson DW, Diehl NN, Elbaz A, Ferrarese C, Ferraris A, Fiske B, Gibson MJ, Gibson R, Hadjigeorgiou GM, Hattori N, Ioannidis JP, Jasinska-Myga B, Jeon BS, Kim Y, Klein C, Kruger R, Kyratzi E, Lesage S, Lin C-H, Lynch T, Maraganore DM, Mellick GD, Mutez E, Nilsson C, Opala G, Park S, Puschmann A, Quattrone A, Sharma M, Silburn PA, Sohn Y, Stefanis L, Tadic V, Theuns J, Tomiyama H, Uitti RJ, Valente E, van de Loo S, Vassilatis DK, Vilariño-Güell C, White LR, Wirdefeldt K, Wszolek ZK, Wu R-M, Farrer MJ, Genetic Epidemiology Of Parkinson's Disease (GEO-PD) Consortium (2011) Association of LRRK2 exonic variants with susceptibility to Parkinson's disease: A case-control study. Lancet Neurol 10, 898-908.

[38] Witoelar A, Jansen IE, Wang Y, Desikan RS, Gibbs JR, Blauwendraat C, Thompson WK, Hernandez DG, Djurovic S, Schork AJ, Bettella F, Ellinghaus D, Franke A, Lie BA, McEvoy LK, Karlsen TH, Lesage S, Morris HR, Brice A, Wood NW, Heutink P, Hardy J, Singleton AB, Dale AM, Gasser T2, Andreassen OA, Sharma M; International Parkinson's Disease Genomics Consortium (IPDGC), North American Brain Expression Consortium (NABEC), and United Kingdom Brain Expression Consortium (UKBEC) Investigators (2017) Genome-wide pleiotropy between Parkinson disease and autoimmune diseases. JAMA Neurol 74, 780-792.

[39] Gilsbach BK, Kortholt A (2014) Structural biology of the LRRK2 GTPase and kinase domains: Implications for regulation. Front Mol Neurosci 7, 32.

[40] Liu Z, Lee J, Krummey S, Lu W, Cai H, Lenardo MJ (2011) The kinase LRRK2 is a regulator of the transcription factor NFAT that modulates the severity of inflammatory bowel disease. Nat Immunol 12, 1063.

[41] Xiong Y, Dawson VL, Dawson TM (2012) LRRK2 GTPase dysfunction in the pathogenesis of Parkinson's disease. Biochem Soc Trans 40, 1074-1079.

[42] Mamais A, Manzoni C, Nazish I, Arber C, Sonustun B, Wray S, Warner TT, Cookson MR, Lewis PA, Ban- 
dopadhyay R (2018) Analysis of macroautophagy related proteins in G2019S LRRK2 Parkinson's disease brains with Lewy Body pathology. Brain Res 1701, 75-84.

[43] Thevenet J, Gobert R, van Huijsduijnen R, Wiessner C, Sagot Y (2011) Regulation of LRRK2 expression points to a functional role in human monocyte maturation. PLoS One 6, e21519.

[44] Gardet A, Benita Y, Li C, Sands BE, Ballester I, Stevens C, Korzenik JR, Rioux JD, Daly MJ, Xavier RJ, Podolsky DK (2010) LRRK2 is involved in the IFN- $\gamma$ response and host response to pathogens. J Immunol 185, 5577-5585.

[45] Hakimi M, Selvanantham T, Swinton E, Padmore RF, Tong Y, Kabbach G, Venderova K, Girardin SE, Bulman DE, Scherzer CR, LaVoie MJ, Gris D, Park DS, Angel JB, Shen J, Philpott DJ, Schlossmacher MG (2011) Parkinson's disease-linked LRRK2 is expressed in circulating and tissue immune cells and upregulated following recognition of microbial structures. J Neural Transm 118, 795-808.

[46] Miklossy J, Arai T, Guo J-P, Klegeris A, Yu S, McGeer EG, McGeer PL (2006) LRRK2 expression in normal and pathologic human brain and in human cell lines. $\mathrm{J} \mathrm{Neu-}$ ropathol Exp Neurol 65, 953-963.

[47] Ryan KJ, White CC, Patel K, Xu J, Olah M, Replogle JM, Frangieh M, Cimpean M, Winn P, McHenry A, Kaskow BJ, Chan G, Cuerdon N, Bennett DA, Boyd JD, Imitola J, Elyaman W, Jager PL, Bradshaw EM (2017) A human microglia-like cellular model for assessing the effects of neurodegenerative disease gene variants. Sci Transl Med 9, eaai7635.

[48] Gillardon F, Schmid R, Draheim H (2012) Parkinson's disease-linked leucine-rich repeat kinase 2(R1441G) mutation increases proinflammatory cytokine release from activated primary microglial cells and resultant neurotoxicity. Neuroscience 208, 41-48.

[49] Moehle MS, Webber PJ, Tse T, Sukar N, Standaert DG, Silva T, Cowell RM, West AB (2012) LRRK2 inhibition attenuates microglial inflammatory responses. J Neurosci 32, 1602-1611.

[50] Liu W, Liu X, Li Y, Zhao J, Liu Z, Hu Z, Wang Y, Yao Y, Miller AW, Su B, Cookson MR, Li X, Kang Z (2017) LRRK2 promotes the activation of NLRC4 inflammasome during Salmonella Typhimurium infection. J Exp Med 214, 3051-3066.

[51] Zhang Q, Pan Y, Yan R, Zeng B, Wang H, Zhang X, Li W, Wei H, Liu Z (2015) Commensal bacteria direct selective cargo sorting to promote symbiosis. Nat Immunol 16, 918926.

[52] Heliö T, Halme L, Lappalainen M, Fodstad H, PaavolaSakki P, Turunen U, Färkkilä M, Krusius T, Kontula K (2003) CARD15/NOD2 gene variants are associated with familially occurring and complicated forms of Crohn's disease. Gut 52, 558.

[53] Heresbach D, Gicquel-Douabin V, Birebent B, D'halluin P-N, Berre N, Dreano S, Siproudhis L, Dabadie A, Gosselin M, Mosser J, Semana G, Bretagne J-F, Yaouanq J (2004) NOD2/CARD15 gene polymorphisms in Crohn's disease. Eur J Gastroenterol Hepatol 16, 55-62.

[54] Ogura Y, Bonen DK, Inohara N, Nicolae DL, Chen FF, Ramos R, Britton H, Moran T, Karaliuskas R, Duerr RH, Achkar J-P, Brant SR, Bayless TM, Kirschner BS, Hanauer SB, Nuñez G, Cho JH (2001) A frameshift mutation in NOD2 associated with susceptibility to Crohn's disease. Nature 411, 603.

[55] Bialecka M, Kurzawski M, Klodowska-Duda G, Opala G, Juzwiak S, Kurzawski G, Tan E-K, Drozdzik M (2007)
CARD15 variants in patients with sporadic Parkinson's disease. Neurosci Res 57, 473-476.

[56] Sterka D, Rati DM, Marriott I (2006) Functional expression of NOD2, a novel pattern recognition receptor for bacterial motifs, in primary murine astrocytes. Glia 53, 322-330.

[57] Beynon V, Cotofana S, Brand S, Lohse P, Mair A, Wagner S, Mussack T, Ochsenkühn T, Folwaczny M, Folwaczny C, Glas J, Török H (2008) NOD2/CARD15 genotype influences MDP-induced cytokine release and basal IL-12p40 levels in primary isolated peripheral blood monocytes. Inflamm Bowel Dis 14, 1033-1040.

[58] Maeda S, Hsu L-C, Liu H, Bankston LA, Iimura M, Kagnoff MF, Eckmann L, Karin M (2005) Nod2 mutation in Crohn's disease potentiates NF- $\kappa$ B activity and IL- $1 \beta$ processing. Science 307, 734-738.

[59] Chauhan VS, Sterka DG, Furr SR, Young AB, Marriott I (2009) NOD2 plays an important role in the inflammatory responses of microglia and astrocytes to bacterial CNS pathogens. Glia 57, 414-423.

[60] Lin JC, Lin CS, Hsu CW, Lin CL, Kao CH (2016) Association between Parkinson's disease and inflammatory bowel disease: A nationwide Taiwanese retrospective cohort study. Inflamm Bowel Dis 22, 1049-1055.

[61] Fujioka S, Curry SE, Kennelly KD, Tacik P, Heckman MG, Tsuboi Y, Strongosky AJ, van Gerpen JA, Uitti RJ, Ross OA, Ikezu T, Wszolek ZK (2017) Occurrence of Crohn's disease with Parkinson's disease. Parkinsonism Relat Disord 37, 116-117.

[62] Villumsen M, Aznar S, Pakkenberg B, Jess T, Brudek T (2018) Inflammatory bowel disease increases the risk of Parkinson's disease: A Danish nationwide cohort study 1977-2014. Gut 68, 18-24.

[63] Villumsen M, Aznar S, Pakkenberg B, Brudek T, Jess T (2018) Authors' response: Association between IBD and Parkinson's disease: Seek and you shall find? Gut 68, 1722.

[64] Weimers P, Halfvarson J, Sachs MC, Saunders-Pullman R, Ludvigsson JF, Peter I, Burisch J, Olén O (2019) Inflammatory bowel disease and Parkinson's disease: A nationwide Swedish cohort study. Inflamm Bowel Dis 25, 111-123.

[65] Peter I, Dubinsky M, Bressman S, Park A, Lu C, Chen N, Wang A (2018) Anti-tumor necrosis factor therapy and incidence of Parkinson disease among patients with inflammatory bowel disease. JAMA Neurol 75, 939-946.

[66] Park S, Kim J, Chun J, Han K, Soh H, Kang E, Lee H, Im J, Kim J (2019) Patients with inflammatory bowel disease are at an increased risk of Parkinson's disease: A South Korean nationwide population-based study. J Clin Med $\mathbf{8}$, 1191.

[67] Ford AC, Achkar J-P, Khan KJ, Kane SV, Talley NJ, Marshall JK, Moayyedi P (2011) Efficacy of 5aminosalicylates in ulcerative colitis: Systematic review and meta-analysis. Am J Gastroenterol 106, 601.

[68] Ríos J, Navarro C, Navarro M, Tapia M, Vera M, Arillo V, García M, Castellanos A, Sevilla F (2019) Association of Parkinson's disease and treatment with aminosalicylates in inflammatory bowel disease: A cross-sectional study in a Spain drug dispensation records. BMJ Open 9, e025574.

[69] Camacho-Soto A, Gross A, Nielsen S, Dey N, Racette BA (2018) Inflammatory bowel disease and risk of Parkinson's disease in Medicare beneficiaries. Parkinsonism Relat Disord 50, 23-28.

[70] Zhu F, Li C, Gong J, Zhu W, Gu L, Li N (2018) The risk of Parkinson's disease in inflammatory bowel disease: A 
systematic review and meta-analysis. Dig Liver Dis 51, 38-42.

[71] Calkins BM (1989) A meta-analysis of the role of smoking in inflammatory bowel disease. Digest Dis Sci 34, 18411854.

[72] Lunney P, Leong R (2012) Review article: Ulcerative colitis, smoking and nicotine therapy. Aliment Pharmacol Ther 36, 997-1008.

[73] Li X, Li W, Liu G, Shen X, Tang Y (2015) Association between cigarette smoking and Parkinson's disease: A meta-analysis. Arch Gerontol Geriatr 61, 510-516.

[74] Derkinderen P, annon K, Brundin P (2014) Gut feelings about smoking and coffee in Parkinson's disease. Mov Disord 29, 976-979.

[75] Quik M (2004) Smoking, nicotine and Parkinson's disease. Trends Neurosci 27, 561-568.

[76] Ritz B, Lee P-C, Lassen CF, Arah OA (2014) Parkinson disease and smoking revisited. Neurology 83, 1396-1402.

[77] Schrag A, Horsfall L, Walters K, Noyce A, Petersen I (2015) Prediagnostic presentations of Parkinson's disease in primary care: A case-control study. Lancet Neurol 14, 57-64.

[78] Gaenslen A, Swid I, Liepelt-Scarfone I, Godau J, Berg D (2011) The patients' perception of prodromal symptoms before the initial diagnosis of Parkinson's disease. Mov Disord 26, 653-658.

[79] Pont-Sunyer C, Hotter A, Gaig C, Seppi K, Compta Y, Katzenschlager R, Mas N, Hofeneder D, Brücke T, Bayés A, Wenzel K, Infante J, Zach H, Pirker W, Posada IJ, álvarez R, Ispierto L, Fàbregues O, Callén A, Palasí A, Aguilar M, Martí M, Valldeoriola F, Salamero M, Poewe W, Tolosa E (2015) The Onset of Nonmotor Symptoms in Parkinson's disease (The ONSET PD Study). Mov Disord 30, 229-237.

[80] Strang R (1965) The association of gastro-duodenal ulceration and Parkinson's disease. Med J Aust 1, 842-3.

[81] Okayasu I, Hatakeyama S, Yamada M, Ohkusa T, Inagaki Y, Nakaya R (1990) A novel method in the induction of reliable experimental acute and chronic ulcerative colitis in mice. Gastroenterology 98, 694-702.

[82] Kishimoto Y, Zhu W, Hosoda W, Sen JM, Mattson MP (2019) Chronic mild gut inflammation accelerates brain neuropathology and motor dysfunction in $\alpha$-synuclein mutant mice. Neuromol Med 21, 239-249.

[83] Fehrenbacher JC, Vasko MR, Duarte DB (2012) Models of inflammation: Carrageenan- or complete Freund's adjuvant (CFA)-induced edema and hypersensitivity in the rat. Curr Protoc Pharmacol 56, 5.4.1-5.4.4.

[84] Hernández-Romero M, Delgado-Cortés M, Sarmiento M, de Pablos RM, Espinosa-Oliva A, Argüelles S, Bández MJ, Villarán RF, Mauriño R, Santiago M, Venero JL, Herrera AJ, Cano J, Machado A (2012) Peripheral inflammation increases the deleterious effect of CNS inflammation on the nigrostriatal dopaminergic system. Neurotoxicology 33, 347-360.

[85] Han Y, Zhao T, Cheng X, Zhao M, Gong S-H, Zhao Y-Q, Wu H-T, Fan M, Zhu L-L (2018) Cortical inflammation is increased in a DSS-induced colitis mouse model. Neurosci Bull 34, 1058-1066.

[86] Garrido-Gil P, Rodriguez-Perez AI, Dominguez-Meijide A, Guerra MJ, Labandeira-Garcia JL (2018) Bidirectional neural interaction between central dopaminergic and gut lesions in Parkinson's disease models. Mol Neurobiol 55, 7297-7316.
[87] Gil-Martínez A-L, Estrada C, Cuenca L, Cano J-A, Valiente M, Martínez-Cáceres C-M, Fernández-Villalba E, Herrero M-T (2019) Local gastrointestinal injury exacerbates inflammation and dopaminergic cell death in parkinsonian mice. Neurotox Res 35, 918-930.

[88] Grathwohl S, Quansah E, Maroof N, Steiner JA, Spycher L, Benmansour F, Duran-Pacheco G, SiebourgPolster J, Oroszlan-Szovik K, Remy H, Haenggi M, Stawiski M, Sehlhausen M, Maliver P, Wolfert A, Emrich T, Madaj Z, Galvis ML, Mueller C, Herrmann A, Brundin P, Britschgi M (2019) Experimental colitis drives enteric alpha-synuclein accumulation and Parkinson-like brain pathology. bioRxiv, 505164; doi: https://doi.org/10.1101/505164.

[89] Resnikoff H, Metzger JM, Lopez M, Bondarenko V, Mejia A, Simmons HA, Emborg ME (2019) Colonic inflammation affects myenteric alpha-synuclein in nonhuman primates. J Inflamm Res 12, 113-126.

[90] Edwards L, Quigley E, Hofman R, Pfeiffer R (1993) Gastrointestinal symptoms in Parkinson disease: 18-month follow-up study. MovDisord 8, 83-86.

[91] Edwards L, Pfeiffer R, Quigley E, Hofman R, Balluff M (1991) Gastrointestinal symptoms in Parkinson's disease. Mov Disord 6, 151-156.

[92] Beach TG, Adler CH, Sue LI, Vedders L, Lue L, Iii CL, Akiyama H, Caviness JN, Shill HA, Sabbagh MN, Walker DG, Arizona Parkinson's Disease Consortium (2010) Multi-organ distribution of phosphorylated $\alpha$-synuclein histopathology in subjects with Lewy body disorders. Acta Neuropathol 119, 689-702.

[93] Wakabayashi K, Takahashi H, Takeda S, Ohama E, Ikuta F (1988) Parkinson's disease: The presence of Lewy bodies in Auerbach's and Meissner's plexuses. Acta Neuropathol 76, 217-221.

[94] Aldecoa I, Navarro-Otano J, Stefanova N, Sprenger FS, Seppi K, Poewe W, Cuatrecasas M, Valldeoriola F, Gelpi E, Tolosa E (2015) Alpha-synuclein immunoreactivity patterns in the enteric nervous system. Neurosci Lett 602, 145-149.

[95] Côté M, Poirier AA, Aubé B, Jobin C, Lacroix S, Soulet D (2015) Partial depletion of the proinflammatory monocyte population is neuroprotective in the myenteric plexus but not in the basal ganglia in a MPTP mouse model of Parkinson's disease. Brain Behav Immun 46, 154-167.

[96] Clairembault T, Leclair-Visonneau L, Coron E, Bourreille A, Dily S, Vavasseur F, Heymann M-F, Neunlist M, Derkinderen P (2015) Structural alterations of the intestinal epithelial barrier in Parkinson's disease. Acta Neuropathol Commun 3, 12.

[97] Hasegawa S, Goto S, Tsuji H, Okuno T, Asahara T, Nomoto K, Shibata A, Fujisawa Y, Minato T, Okamoto A, Ohno K, Hirayama M (2015) Intestinal dysbiosis and lowered serum lipopolysaccharide-binding protein in Parkinson's disease. PLoS One 10, e0142164.

[98] Gelpi E, Navarro-Otano J, Tolosa E, Gaig C, Compta Y, Rey M, Martí M, Hernández I, Valldeoriola F, Reñé R, Ribalta T (2014) Multiple organ involvement by alphasynuclein pathology in Lewy body disorders. Mov Disord 29, 1010-1018.

[99] Yu YB, Li YQ (2014) Enteric glial cells and their role in the intestinal epithelial barrier. World J Gastroenterol 20, 11273-11280.

[100] Grubišić V, Gulbransen BD (2017) Enteric glia: The most alimentary of all glia. J Physiol 595, 557-570. 
[101] Clairembault T, Leclair-Visonneau L, Neunlist M, Derkinderen P (2015) Enteric glial cells: New players in Parkinson's disease? Mov Disord 30, 494-498.

[102] Savidge TC, Sofroniew MV, Neunlist M (2007) Starring roles for astroglia in barrier pathologies of gut and brain. Lab Invest 87, 3700600 .

[103] Cirillo C, Sarnelli G, Esposito G, Turco F, Steardo L, Cuomo R (2011) S100B protein in the gut: The evidence for enteroglial-sustained intestinal inflammation. World $J$ Gastroenterol 17, 1261-1266.

[104] Forsyth CB, Shannon KM, Kordower JH, Voigt RM, Shaikh M, Jaglin JA, Estes JD, Dodiya HB, Keshavarzian A (2011) Increased intestinal permeability correlates with sigmoid mucosa alpha-synuclein staining and endotoxin exposure markers in early Parkinson's disease. PLoS One 6, e28032.

[105] Rühl A, Franzke S, Collins S, Stremmel W (2001) Interleukin-6 expression and regulation in rat enteric glial cells. Am J Physiol Gastrointest Liver Physiol 280, G11631171.

[106] Neurath MF (2014) Cytokines in inflammatory bowel disease. Nat Rev Immunol 14, 329-342.

[107] Leal MC, Casabona JC, Puntel M, Pitossi FJ (2013) Interleukin- $1 \beta$ and tumor necrosis factor- $\alpha$ : Reliable targets for protective therapies in Parkinson's disease? Front Cell Neurosci 7, 53.

[108] Wright EK, Kamm MA, Cruz P, Hamilton AL, Ritchie KJ, Keenan JI, Leach S, Burgess L, Aitchison A, Gorelik A, Liew D, Day AS, Gearry RB (2016) Comparison of fecal inflammatory markers in Crohn's disease. Inflamm Bowel Dis 22, 1086-1094.

[109] Prigent A, Lionnet A, Durieu E, Chapelet G, Bourreille A, Neunlist M, Rolli-Derkinderen M, Derkinderen P (2019) Enteric alpha-synuclein expression is increased in Crohn's disease. Acta Neuropathol 137, 359-361.

[110] Park J, Paik SR, Jou I, Park S (2008) Microglial phagocytosis is enhanced by monomeric $\alpha$-synuclein, not aggregated $\alpha$-synuclein: Implications for Parkinson's disease. Glia 56, 1215-1223.

[111] Venezia S, Refolo V, Polissidis A, Stefanis L, Wenning GK, Stefanova N (2017) Toll-like receptor 4 stimulation with monophosphoryl lipid A ameliorates motor deficits and nigral neurodegeneration triggered by extraneuronal $\alpha$-synucleinopathy. Mol Neurodegener 12, 52.

[112] Stolzenberg E, Berry D, Yang D, Lee EY, Kroemer A, Kaufman S, Wong G, Oppenheim JJ, Sen S, Fishbein T, Bax A, Harris B, Barbut D, Zasloff MA (2017) A role for neuronal alpha-synuclein in gastrointestinal immunity. $J$ Innate Immun 9, 456-463.

[113] Haenseler W, Zambon F, Lee H, Vowles J, Rinaldi F, Duggal G, Houlden H, Gwinn K, Wray S, Luk KC, Wade-Martins R, James WS, Cowley SA (2017) Excess $\alpha$-synuclein compromises phagocytosis in iPSC-derived macrophages Sci Rep 7, 9003.

[114] Böttner M, Zorenkov D, Hellwig I, Barrenschee M, Harde J, Fricke T, Deuschl G, Egberts J-H, Becker T, FritscherRavens A, Arlt A, Wedel T (2012) Expression pattern and localization of alpha-synuclein in the human enteric nervous system. Neurobiol Dis 48, 474-480.

[115] Gray MT, Munoz DG, Gray DA, Schlossmacher MG, Woulfe JM (2014) Alpha-synuclein in the appendiceal mucosa of neurologically intact subjects. Mov Disord 29, 991-998.

[116] Killinger BA, Madaj Z, Sikora JW, Rey N, Haas AJ, Vepa Y, Lindqvist D, Chen H, Thomas PM, Brundin P, Brundin
L, Labrie V (2018) The vermiform appendix impacts the risk of developing Parkinson's disease. Sci Transl Med 10, eaar5280.

[117] Massey AR, Beckham DJ (2016) Alpha-synuclein, a novel viral restriction factor hiding in plain sight. DNA Cell Biol 35, 643-645.

[118] Labrie V, Brundin P (2017) Alpha-synuclein to the rescue: Immune cell recruitment by alpha-synuclein during gastrointestinal infection. J Innate Immun 9, 437-440.

[119] Carabotti M, Scirocco A, Maselli M, Severi C (2015) The gut-brain axis: Interactions between enteric microbiota, central and enteric nervous systems. Ann Gastroenterol 28, 203-209.

[120] Frank DN, Amand AL, Feldman RA, Boedeker EC, Harpaz N, Pace NR (2007) Molecular-phylogenetic characterization of microbial community imbalances in human inflammatory bowel diseases. Proc Natl Acad Sci U S A 104, 13780-13785.

[121] Peterson DA, Frank DN, Pace NR, Gordon JI (2008) Metagenomic approaches for defining the pathogenesis of inflammatory bowel diseases. Cell Host Microbe 3, 417-427.

[122] Scheperjans F, Aho V, Pereira PA, Koskinen K, Paulin L, Pekkonen E, Haapaniemi E, Kaakkola S, Eerola-Rautio J, Pohja M, Kinnunen E, Murros K, Auvinen P (2015) Gut microbiota are related to Parkinson's disease and clinical phenotype. Mov Disord 30, 350-358.

[123] Hopfner F, Künstner A, Müller SH, Künzel S, Zeuner KE, Margraf NG, Deuschl G, Baines JF, Kuhlenbäumer G (2017) Gut microbiota in Parkinson disease in a northern German cohort. Brain Res 1667, 41-45.

[124] Petrov V, Saltykova I, Zhukova I, Alifirova V, Zhukova N, Dorofeeva YB, Tyakht A, Kovarsky B, Alekseev D, Kostryukova E, Mironova YS, Izhboldina O, Nikitina M, Perevozchikova T, Fait E, Babenko V, Vakhitova M, Govorun V, Sazonov A (2017) Analysis of gut microbiota in patients with Parkinson's disease. Bull Exp Biol Med 162, 734-737.

[125] Bedarf J, Hildebrand F, Coelho L, Sunagawa S, Bahram M, Goeser F, Bork P, Wüllner U (2017) Functional implications of microbial and viral gut metagenome changes in early stage L-DOPA-naive Parkinson's disease patients. Genome Med 9, 39.

[126] Sampson TR, Debelius JW, Thron T, Janssen S, Shastri GG, Ilhan ZE, Challis C, Schretter CE, Rocha S, Gradinaru V, Chesselet M-F, Keshavarzian A, Shannon KM, Krajmalnik-Brown R, Wittung-Stafshede P, Knight R, Mazmanian SK (2016) Gut microbiota regulate motor deficits and neuroinflammation in a model of Parkinson's disease. Cell 167, 1469-1480.e12.

[127] Erny D, de Angelis A, Jaitin D, Wieghofer P, Staszewski O, David E, Keren-Shaul H, Mahlakoiv T, Jakobshagen K, Buch T, Schwierzeck V, Utermöhlen O, Chun E, Garrett WS, McCoy KD, Diefenbach A, Staeheli P, Stecher B, Amit I, Prinz M (2015) Host microbiota constantly control maturation and function of microglia in the CNS. Nat Neurosci 18, 965-977.

[128] Bravo JA, Forsythe P, Chew MV, Escaravage E, Savignac HM, Dinan TG, Bienenstock J, Cryan JF (2011) Ingestion of Lactobacillus strain regulates emotional behavior and central GABA receptor expression in a mouse via the vagus nerve. Proc Natl Acad Sci U S A 108, 16050-16055.

[129] Holmqvist S, Chutna O, Bousset L, Aldrin-Kirk P, Li W, Björklund T, Wang Z-Y, Roybon L, Melki R, Li J-Y (2014) Direct evidence of Parkinson pathology spread from the 
gastrointestinal tract to the brain in rats. Acta Neuropathol 128, 805-820.

[130] Berge N, Ferreira N, Gram H, Mikkelsen T, Alstrup A, Casadei N, Tsung-Pin P, Riess O, Nyengaard J, Tamgüney G, Jensen P, Borghammer P (2019) Evidence for bidirectional and trans-synaptic parasympathetic and sympathetic propagation of alpha-synuclein in rats. Acta Neuropathol, doi: 10.1007/s00401-019-02040-w

[131] Braak H, Tredici K, Rüb U, de Vos R, Steur E, Braak E (2003) Staging of brain pathology related to sporadic Parkinson's disease. Neurobiol Aging 24, 197-211.

[132] Kim S, Kwon S-H, Kam T-I, Panicker N, Karuppagounder SS, Lee S, Lee J, Kim W, Kook M, Foss CA, Shen C, Lee H, Kulkarni S, Pasricha PJ, Lee G, Pomper MG, Dawson VL, Dawson TM, Ko H (2019) Transneuronal propagation of pathologic $\alpha$-synuclein from the gut to the brain models Parkinson's disease. Neuron 103, 627-641.e7.

[133] Pan-Montojo F, Schwarz M, Winkler C, Arnhold M, O'Sullivan GA, Pal A, Said J, Marsico G, Verbavatz JM, Rodrigo-Angulo M, Gille G, Funk RH, Reichmann H (2012) Environmental toxins trigger PD-like progression via increased alpha-synuclein release from enteric neurons in mice. Sci Rep 2, 898.

[134] Manfredsson FP, Luk KC, Benskey MJ, Gezer A, Garcia J, Kuhn NC, Sandoval IM, Patterson JR, O'Mara A, Yonkers R, Kordower JH (2018) Induction of alpha- synuclein pathology in the enteric nervous system of the rat and non-human primate results in gastrointestinal dysmotility and transient CNS pathology. Neurobiol Dis 112, 106-118.

[135] Lionnet A, Leclair-Visonneau L, Neunlist M, Murayama S, Takao M, Adler CH, Derkinderen P, Beach TG (2018) Does Parkinson's disease start in the gut? Acta Neuropathol 135, 1-12.

[136] Liu B, Fang F, Pedersen NL, Tillander A, Ludvigsson JF, Ekbom A, Svenningsson P, Chen H, Wirdefeldt K (2017) Vagotomy and Parkinson disease. Neurology 88, 19962002.

[137] Svensson E, Horváth-Puhó E, Thomsen RW, Djurhuus J, Pedersen L, Borghammer P, Sørensen H (2015) Vagotomy and subsequent risk of Parkinson's disease. Ann Neurol 78, 522-529.

[138] Tysnes O, Kenborg L, Herlofson K, Steding-Jessen M, Horn A, Olsen JH, Reichmann H (2015) Does vagotomy reduce the risk of Parkinson's disease? Ann Neurol 78, 1011-1012.

[139] Siderowf A, Lang AE (2012) Premotor Parkinson's disease: Concepts and definitions. Mov Disord 27, 608-616.

[140] Johnson ME, Stecher B, Labrie V, Brundin L, Brundin P (2018) Triggers, facilitators, and aggravators: Redefining Parkinson's disease pathogenesis. Trends Neurosci 42, 4-13. 